\section{USAGE OF INTRA-AORTIC BALLOON PUMP IN HIGH RISK CORONARY ARTERY BYPASS GRAFT SURGERY}

Patients presenting with severe left ventricular (LV) dysfunction undergoing coronary artery bypass surgery are a difficult subset to treat and are at an increased risk of perioperative morbidity and mortality. Current treatment options for this high-risk group of patients include intensive medical therapy, surgical revascularization, ventricular remodeling, and heart transplantation. Medical treatment alone is problematic because of limited longterm survival. ${ }^{[1,3]}$ As the proportion of highrisk patients for cardiac surgery increases, use of intra-aortic balloon counterpulsation (IABP) has increased, especially as part of preoperative therapy. The routine preoperative use of IABP in high-risk patient population has had favorable reports from some investigators.

The Coronary Artery Surgery Study (CASS) study demonstrated that only $38 \%$ of medically treated patients $(E F<35 \%)$ were alive and free of moderate or severe limitation of symptoms after 5 years of treatment. ${ }^{[1]}$ Intraaortic balloon pump (IABP) is widely used to provide circulatory support for patients experiencing hemodynamic instability due to myocardial infarction, cardiogenic shock, or in very high risk patients undergoing angioplasty or coronary artery bypass grafting. IABP was first employed over three decades ago as a treatment of last resort for terminally ill patients suffering from cardiogenic shock.

The American College of Cardiology/American Heart Association guideline indications for IABP use in acute myocardial infarction include preparation for angiography and revascularization in cardiogenic shock that has not quickly reversed, acute mitral regurgitation or ventricular septal defect, refractory post-MI angina, refractory ventricular arrhythmias with hemodynamic instability, poor left ventricular function or recurrent ischemia. ${ }^{[4]}$ Beneficial effects of preoperative intra-aortic balloon pump treatment on outcome and cost in high-risk patients who have coronary artery bypass grafting have been demonstrated in various studies. ${ }^{[5]}$ Cardiopulmonary bypass time was shorter in the IABP group and the incidence of postoperative low cardiac output was also significantly lower in them. Intubation time, length of stay in the intensive care unit and hospital stay were also shorter in the IABP group. ${ }^{[5,6]}$ Even in high-risk off pump coronary artery bypass graft surgery routine, preoperative insertion of IABP reduced the incidence of acute renal failure and helped in earlier discharge of the patients. However there was no difference in mortality rates in those who had IABP when compared with patients without the IABP. ${ }^{[7]}$

Use of IABP is associated with certain complications, including peripheral ischemia, infection, and hematological derangements. The incidence of vascular complications reported in literature ranges from 8.7 to $20 \%$. ${ }^{[8]}$ There are reports of in-hospital mortality being significantly lower in patients treated preoperatively with IABP compared with patients treated postoperatively. ${ }^{[9]}$ There is a clear relationship between duration of treatment and balloon-related complications. Independent risk factors for balloon-related complications are longer treatment time, acute myocardial infarction, age over 65 years and ejection fraction less than $30 \%$. The benchmark registry included worldwide prospectively collected data from 203 hospitals on 16909 patients, who received IABP between June
1996 and August 2000. ${ }^{[10]}$ The registry reported overall IABP-related morbidity of $2.6 \%$ and IABP-related mortality of $0.05 \%$. Female sex, old age and peripheral vascular disease were reported as independent predictors of major complications. Severity of coronary artery disease and left ventricular aneurysm surgery were found to be an independent risk factor. Many of these patients had unstable angina, hemodynamic instability and cardiac arrhythmias as indications of IABP insertion, which were also found to be independent risk factors for vascula complications. These factors reflect the severity of underlying cardiac dysfunction. Davoodi et al. ${ }^{[11]}$ have interesting observations. In their study involving over eight hundred high-risk cases the use of IABP was associated with prolonged hospital stay and independently predicted mortality at 1 month.

The decision to insert IABP may b individualized and best left to the treating physician as there are varying reports indicating differing outcomes.

\section{REFERENCES}

1. Alderman EL, Fisher LD, Litwin P, Kaiser GC, Myers WO, Maynard C, et al. Results of coronary artery surgery in patients with poor left ventricular function (CASS). Circulation 1983;68:785-95

2. Zubiate P, Kay JH, Mendez AM. Myocardial revascularization for the patient with drastic impairment of function of the left ventricle. J Thorac Cardiovasc Surg 1977;73:84-6.

3. Passamani E, Davis KB, Gillespie MJ, Killip T. A randomized trial of coronary artery bypass surgery: Survival of patients with a low ejection fraction. N Engl J Med 1985;312:1665-71.

4. Ryan TJ, Anderson JL, Antman EM, et al. ACC/ 
AHA guidelines for the management of patients with acute myocardial infarction. J Am Coll Cardiol 1996;28:1328-419.

5. Christenson JT, Simonet F, Badel P, Schmuziger M. Optimal timing of preoperative intraaortic balloon pump support in high-risk coronary patients. Ann Thorac Surg 1999;68:934-9.

6. Christenson JT, Badel P, SimonetF, Schmuziger M. Preoperative intraaortic balloon pump enhances cardiac performance and improves the outcome of redo CABG. Ann Thorac Surg 1997;64: 1237-44.

7. Vora HA, Dmitri WR. Elective intraaortic balloon counterpulsation in high risk offpump coronary artery bypass grafting. J Card Surg ;21:1-5.

8. Barnett MG, Swartz MT, Peterson GJ, Naunheim KS, Pennington DG, Vaca KJ, et al. Vascular complications from intra-aortic balloons: Risk analysis. J Vasc Surg 1994;19:81-9.

9. Christenson JT, Cohen M, Ferguson JJ 3rd,
Freedman RJ, Miller MF, Ohman EM, et al. Trends in intraaortic balloon counterpulsation complications and outcomes in cardiac surgery. Ann Thorac Surg 2002;74:1086-90.

10. Ferguson JJ 3rd, Cohen M, Freedman RJ, Stone GW, Miller MF, Joseph DL, et al. The current practice of intra-aortic balloon counterpulsation: Results from the Benchmark Registry. J Am Coll Cardiol 2001;38:1456-62.

11. Davoodi S, Karimi A, Ahmadi SH, Marzban M, Movahhedi N, Abbasi K, et al. Coronary artery bypass grafting in patients with low ejection fraction: The effect of intra-aortic balloon pump insertion on early outcome. Indian J Med Sci 2008;62:[***in current issue].

K. JAI SHANKAR

Institute of Cardiovascular Diseases, Madras Medical Mission, 4 A, Dr. J.J. Nagar, Mogappair, Chennai 600 037, India. E-mail:drkjs68@yahoo.com 